\title{
Do Pay-for-Grades Programs Encourage Student Cheating? Evidence from a randomized experiment
}

\author{
Tao Li \\ Department of Government and Public Administration \\ University of Macau \\ Yisu Zhou \\ Faculty of Education \\ University of Macau \\ Working paper version: November 17, 2017 \\ Abstract \\ Pay-for-grade programs were adopted in many schools within the past two \\ decades. Despite doubts over its effectiveness in improve students perfor- \\ mances, educators worry that monetary incentive could skew student learn- \\ ing motivation and lead to academic cheating. Due to data limitation, there \\ has been scant empirical study on this issue. Using a randomized control trial \\ in Chinese migrant primary schools, we studied the effects of pay-for-grades \\ programs on academic cheating. We provide new insights into the feasibil- \\ ity of such policy to improve learning outcomes, show concerning levels of \\ cheating in Chinese migrant schools, and discuss its policy implications.
}

Keywords: pay-for-grades; cheating; randomized control trial; China; primary school

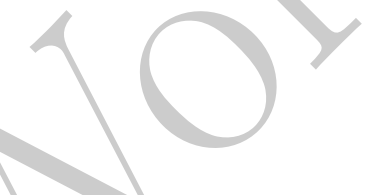

\section{Introduction}

Using financial incentive to stimulate student schooling outcomes are not new ideas. Ravitch (2000) documented that New York city promised to reward children financially on the basis of school performance as early as 1820s. Long been regarded as a fringe idea in education community, this approach has resurfaced as a developmental and education policy tool in recent years. There are many iterations of this approach (Slavin, 2010): some uses cash to encourage school attendance, some steer children for better grades, some for educational attainment, while others for interaction among peers. These policies hinge on

Author of correspondence: Yisu Zhou, 3022 Faculty of Education E33, University of Macau, Av. da Universidade, Taipa, Macau SAR, Email: yisu.zhou@gmail.com, Tel: +853-8822-8722 
the assumption that families and children will be incentivized to engaged in well-specified behaviors given financial transfer (Bettinger, 2012). Researchers have been debating the merits of such programs but judging by current roll-outs, similar policies are likely to stay. According to an extensive review by Slavin (2010), more than a dozen of various programs of similar nature are being tested in developing countries and even among the developed nations. Israel, UK, and the USA are conducting experimentations.

But doubts over whether monetary incentive would skew student learning motivation and lead to unintended consequences, such as academic cheating, remains a concern. Specifically, when targeted behaviors are aspirational, such as improving grades at the end of a semester it is possible that some students will take the shortcut cheat in the test without really trying harder at learning (Cizek, 1999). In other cases when the short-term stakes are high, invigilators, teachers, and administrators may even help students cheat (Jacob \& Levitt, 2003). Though these are valid concerns in their own rights, empirical evidence on this very issue is limited.

In this study, we evaluate the effects of a common cash transfer program: pay-forgrades, on academic cheating. Such programs are designed for the sole purpose of improving learning outcomes through paying students for good grades or test scores (Le, 2015). Using a randomized control trial in Chinese migrant primary schools Beijing, we studied whether students who sit next to each other would copy from one another during standardized tests once they are incentivized by the pay-for-grades program. We provide new insights into the feasibility of this policy tool to improve learning outcomes, show concerning levels of cheating in Chinese migrant schools, and discuss its policy implications.

\section{Literature Review}

\section{Pay-for-grades in schools}

Traditionally the focus of many education system, including China, is to improve school enrollment and keep children inside. This focus is reflected in the United Nation's millennium development goals (MDGs) where universal primary education is one of the priorities. This is where the popular conditional cash transfer programs (CCTs) emerged as policy leverage. Building on the promise of expectancy value theory of achievement (Atkinson, 1957; Eccles, 1983; Wigfield, 1994), it was argued that paying directly to parents and students will improve their motivation to invest in schooling (See Morais de Sa e Silva, 2015 for a review). It did not take long, however, for many educational researchers to realize that the basic CCTs do not necessarily improve learning outcomes (e.g., Simões \& Sabates, 2014). A few upgraded CCTs implemented in Nicaragua, the USA (Opportunity NYC), Bangladesh, Cambodia, and Pakistan went one step further to make CCT contingent on satisfactory student academic performance (Morais de Sa e Silva, 2015).

In addition to keeping students inside schools, there is also an increasing number of special CCTs designed with the goal of improving learning outcomes through paying students for good grades or test scores (so-called pay-for-grades programs). Scholarly interest in such programs has surged. In a meta-analysis, Le (2015) identified 18 randomized control 
trials (i.e. experiments) of pay-for-grade programs targeting disadvantaged students in the past decade. She found overall weak and positive achievement gains but the gains varying depending on the subject matter being tested, with mathematics showing the most gains while reading and language arts showing zero gains.

Despite these potential benefits, using money to motivate student learning may produce a negative side effect - cheating. Behrman, Parker, Todd, and Wolpin (2015) reported extensive student cheating when monetary rewards were promised if their mathematics scores were improved during the test. This side effect is likely to be serious in developing countries whose educational system is long known to be plagued by various forms of cheating and corruption (Alutu \& Aluede, 2006; Heyneman, 2004; Heyneman, Anderson, \& Nuraliyeva, 2007; Kobiowu \& Alao, 2009; Osipian, 2009; Vlaardingerbroek, Shehab, \& Alameh, 2011). Indian parents scaling the school wall to help their children cheat on the important secondary school exit exam in 2015 is just one recent example(Dearden, 2015). However, despite discussion in Behrman et al. (2015), there has not been research on the relationship between cheating and student performance incentive programs.

\section{Academic cheating}

Academic cheating is regarded to be a significant issue at all levels of education. Cizek (1999) reported that one third of students in elementary schools admit to cheating in some form. In the U.S., over $60 \%$ of middle school and high school students believed that cheating is a serious issue in their school (Evans \& Craig, 1990). Large-scale cheating by both teachers and students was repeatedly reported by the media and researchers (Davis, Drinan, \& Gallant, 2009).

From individual perspective, McCabe (2005) found that getting good grade is the chief motive for students. Researchers have consequently found that the occurrence of cheating is associated with student's self-efficacy and school identification (Finn \& Frone, 2004; Murdock, Hale, \& Weber, 2001). There were multiple reports cited in Cizek's review (1999) that cheating is inversely correlated with student achievement, though recent study depicts a more complicated relationship (Finn \& Frone, 2004).

Cheating also appears to be influenced by cultural factors. Previous studies suggest that cheating is more likely to be perceived as acceptable in more collective Asian societies as in Japan (Diekhoff, Labeff, Shinohara, \& Yasukawa, 1999) and the Middle East (McCabe, Feghali, \& Abdallah, 2008; Vlaardingerbroek et al., 2011). China appears to fall in this same category as well. Based on case studies of essay writing behaviors of Chinese students attending foreign higher institutions, Gu and Brooks (2008) and Shei (2005) argue that in the Chinese learning culture, a substantial period of imitation is generally emphasized for beginners. Cheating, taking the form of copying from one anther, is thus seen more as an effort to achieve competency.

From a sociological perspective, cheating could also be conceived as a means of rebellion toward perceived social injustice or alienation. Murdock et al. (2001) found that middle schoolers who perceived their teachers to be not caring or incompetent are more likely to report cheating as as a means to show that they could also break from school 
rules. Based on his extensive fieldwork in Chinese migrant schools as well as surveys and interviews, Xiong (2015) demonstrated the existence of anti-school subculture in migrant schools that rejects the values of formal schooling entirely. The students, who are denied of admission into public school systems due to their migrant status, defied traditional learning culture. The normative environment of migrant students appears to be highly conductive to cheating.

To summarize, previous literature on academic cheating suggests motivational and sociological links to cheating behavior. Although pay-for-grades program use financial incentive as the main motive, currently no research has empirically examined whether it increases academic cheating in schools or not. The migrant school setting in China provides an ideal test ground for this study. Students mostly come from low socioeconomic background that is the target of pay-for-grade policies.

\section{Research Methods}

\section{Experiment Design and Implementation}

We designed this study based on the pay-for-grade experiment by Li, Han, Zhang, and Rozelle (2014), which was implemented in 11 Beijing migrant schools, chosen randomly from a comprehensive list of 340 migrant schools in Beijing in August 2009.

The experimenters implemented two multiple-choice tests, the baseline test in September 2009 and the evaluation test in January 2010. In addition, a survey was implemented at the baseline stage to collect basic background information. The experimenters also collected classroom seating tables.

The baseline test had approximately 30 math and 30 Chinese multiple-choice questions. Each question may have 2-4 choices. Students were given 45 minutes to answer the questions. All classes in the same grade used the same test. Different grades used different tests. All tests were designed by an external expert panel. The tests were designed to resemble standard tests that students in Chinese schools are accustomed to taking. Student took the test in their regular class time and regular classrooms. Before the test, they were told that the test was organized by a renowned research institution; the test results were not going to be disclosed to their teachers or parents. The tests were supervised by the experimenters to minimize the possibility of cheating by teachers and administrators. In each classroom room, one teacher and one enumerator acted as exam proctors, and one or two additional enumerators walked around the test rooms as monitors. The tests were graded by computers.

The evaluation tests were designed to be similar to the baseline tests in format yet different in substance, taking into account that students had received an additional semester's worth of education.

The experiment focused on students in grades 3 through 6 . Younger students would have difficulties filling out the survey questions by themselves. Each grade typically has one to three classes. Within each school, the experimenters randomly selected several classes in 
grades $3,4,5$ and 6 , under the condition that each grade has one or two classes included in the study. In total, 82 classes were enrolled in the study. Every attending student in these classes participated in the tests and survey.

Each class in the study either hosted the pay-for-grades experiment (referred to as an experiment class or treatment class) or did not host an experiment at all (referred to as a control class). The experimenters then randomly divided these 82 classes into control and treatment groups, with at least one class per grade per school in the treatment group. To make sure that control and treatment classes were truly similar to each other, the experimenters tested the between-group differences of the baseline test scores and 13 survey question responses using t-tests. If there is one t-test result that is statistically significant at the $90 \%$ level (more conservative than $95 \%$ in this context), the experimenters would re-divide the 82 classes into two groups randomly, do the t-tests, and so on until no t-test results are statistically significant at the $90 \%$ level. This procedure guarantees that the treatment and control groups were balanced (i.e., similar to each other) at least in terms of the baseline test scores and 13 survey responses.

Not everyone in the treatment classes actually received the treatment (i.e., the payfor-grades program). Each experiment class had approximately ten treated students randomly selected from the group of the lowest twenty students based upon their baseline test scores.

The pay-for-grades program offered to the treated students resembles a merit-based competitive scholarship program. The experimenters promised to pay 100 RMB (approximately 13 U.S. dollars or between one-third and one-quarter of a semester's tuition) to the treated student with the greatest increase in test scores between the baseline test and the evaluation test in the pay-for-grades experiment classes. The second and third place runner-ups were promised $50 \mathrm{RMB}$ each. This was a within-class competition. Only three treated students who made the largest improvement were entitled to scholarship. Students were also promised a public ceremony and honorary certificates for the winners.

Students in control classes only took the baseline and evaluation tests; no program was offered to them. After dropping some classes for which seating tables were not available, we obtained 42 pay-for-grades treatment classes and 28 control classes that can be used to study cheating. Our analytical sample was comprised of a treatment group of the treated lowest performing students in these pay-for-grades classes and the control group of lowest performing twenty students in these control classes.

\section{Constructing a Cheating Index}

We used the method developed by Wollack $(1997,2004)$ to detect cheating in our multiple-choice exams based on its high statistical power (Romero, Riascos, \& Jara, 2014).

To calculate the $\omega$ index defined by Wollack (1997), a researcher must first identify a pair of two students, and then designate one of them as a potential copier and the other as a source. The index is only defined for the copier. If the researcher switches the copier 
and source statuses, the index will change. The index for the copier is then constructed by comparing the observed number of identical answers and the theoretical number of identical answers predicted by a nominal response model under the assumption of no cheating.

Our context was friendly to the application of this index. First of all, we knew the seating arrangements for all students in our analytical sample. We did not have to make nonfalsifiable assumptions about who copied from whom in a given classroom when no seating information was available. ${ }^{1}$ Second, we focused on the lowest performing students, who were probably more likely to be copiers not only because their higher-performing benchmates afforded them opportunities to do so but also because their benchmates presumably had little interest in copying from them.

For a given pair of students, we, following Wollack $(1997,2004)$, define the $\omega$ index for student $j$ (a potential cheater/copier) as

$$
\omega_{j}=\frac{(\text { number of identical answers })-\text { mean }}{\text { standard error }}
$$

where the mean and standard error are estimated population mean and standard error of the underlying distribution for the number of identical answers between these two students if there is no cheating (i.e, if all matches of answers rise out of randomness).

The definition of the $\omega$ index follows the spirit of the standard hypothesis testing procedure. Suppose the null hypothesis is that no cheating occurs. In other words, all matches of answers rise out of pure randomness. The $\omega$ index is simply the familiar test statistic that measures how unlikely we may observe the data if the null hypothesis is true. We may reject the null if the test statistic is far away from zero. Wollack (2004) called cases of $\omega>1.65$ as displaying some evidence for cheating. The pair of students must come up with a large percentage of identical answers to make $\omega>1.65$. We may observe $\omega>1.65$ purely by chance approximately $5 \%$ of the time (i.e., the type I error rate). Or put it differently, if no cheating occurs for this pair of students, the chance for us to observe such a large number of identical answers is only $5 \%$. In our analysis, we define a binary variable called Cheater, with

$$
\text { Cheater }_{j}= \begin{cases}1 & \text { if } \omega_{j}>1.65 \\ 0 & \text { otherwise }\end{cases}
$$

It is important to emphasize that all statistical algorithms designed to detect cheating, including ours, is only able to detect severe cheating. Say, we may be able to detect a student coping 20 out of 30 questions from his benchmate, but are unable to detect a student copying 1 out of 30 questions. Of course, we do not think that copying only one

\footnotetext{
${ }^{1}$ Behrman et al. (2015) studied the effects of three types of cash incentive treatments (incentives to student only, incentives to teachers only, and incentives to both of them) on high school student test scores in Mexico using a randomized control trial. They find that higher rates of student copying contribute to positive treatment effects on learning. However, they had no classroom seating data and had to make unverifiable assumptions when they study cheating behaviors.
} 
answer is not cheating. It is simply not possible for a statistical algorithm to detect such a mild case of cheating. Our definition of cheating indicator underestimates the existence of cheating. In other words, when our statistical method denotes someone to be a cheater, this person most likely did cheat; when our statistical method denotes someone to be a non-cheater, this person may still have cheated, but his cheating was not severe enough to catch the attention of the statistical algorithm.

Because all tests in our study include a math part and a Chinese part, we calculated the cheating index for these two parts separately.

\section{Regression Specifications}

We first studied how test scores were affected by the pay-for-grades program and other variables using the following regression equation.

$$
\text { score }_{i}=\alpha_{1}+\beta_{1} \text { Treatment }_{i}+\mathbf{X}_{\mathbf{i}} \gamma_{\mathbf{1}}+\epsilon_{\mathbf{i}}
$$

where score represent the standardized math or Chinese scores from the baseline and evaluation tests. Treatment was the treatment status variable ( 1 for treatment students, 0 for control students). The matrix $\mathbf{X}_{\mathbf{i}}$ included the following control variables: Cheater, Pre-test (the average of standardized math and Chinese scores from the baseline, used only when the outcome variable is test scores in the evaluation tests), Male (1 for boys and 0 for girls), Benchmate pre-test (baseline Pre-test of the benchmate), as well as the grade dummies for each grade. Grade 3 dummy is defined as 1 for grade 3 and 0 otherwise. Grade 4, 5, 6 are defined similarly. Grade 4, 5, 6 dummies are included in the regression (Grade 3 dummy dropped to avoid multicollinearity). Standard errors throughout the paper were clustered at the class level. $\beta_{1}$ captured the treatment effect on test scores.

We used the following Probit regression to study to what extent cheating behaviors were affected by the existence of pay-for-grades program and other variables:

$$
\operatorname{Pr}\left(\text { Cheater }_{i}=1\right)=\alpha_{2}+\beta_{2} \text { Treatment }_{i}+\mathbf{X}_{\mathbf{i}} \gamma_{\mathbf{2}}+\epsilon_{\mathbf{i}}
$$

where the matrix $\mathbf{X}_{\mathbf{i}}$ includes the following control variables: Pre-test, Male, Benchmate pre-test, as well as the grade dummies. $\beta_{2}$ captures the treatment effect on cheating; it is the the focus of this paper.

Every student has four observations in our data (baseline math, baseline Chinese, evaluation math, evaluation Chinese). In total, we have 610 students and 1220 observations for either the baseline or evaluation stage. We first run the above regressions for math and Chinese subsamples separately, and then for the full sample, at the baseline or evaluation stage. In the full-sample case, we also add the Math Exam dummy variable (1 for math and 0 for Chinese) to capture any potential systematic differences across these two tests. We did not use the average of math and Chinese score as a dependent variable. In specifications when include these scores, the results are essentially the same. 
The baseline survey contained more variables that could be potentially added to the above regressions. We did not choose to add more variables because the analytical sample size will be further reduced when we add more control variables that contain missing values. More importantly, for a well-balanced experiment study with a large sample size, adding more control variable will not systematically change the size of the estimated treatment effects.

\section{Main Results}

\section{Data Summary}

Table 1 shows summary statistics for our data, by control and treatment status. A simple t-test result is also reported for each variable. For all variables except Male, there was no significant difference between the control and treatment group in the baseline stage (part A). As expected, students in our sample had lower test scores compared to their benchmates.

Overall cheating intensities differ by subject and time. Cheating on the math test showed more fluctuations. The most intensive cheating occurred for the math test in the baseline period, with $19.1 \%$ of the control group and $16.7 \%$ of the treatment group defined as cheaters. However, in the evaluation period, these two numbers dropped to $6.3 \%$ and $5.8 \%$. Cheating was relatively stable for the Chinese test (approximately $10 \%$ in all cases). We will discuss the observed variations of cheating incidents in the next section.

$<$ Table 1 about here. $>$

\section{Determinants of Test Scores}

We first applied Regression 3 to the baseline sample, using baseline math and Chinese scores as the outcome variable. The results are reported in Column 1 (math test only), 2 (Chinese test only), and 3 (both tests) of Table 2. The estimated effects of the treatment status were all insignificant. An insignificant effect of treatment status meant that there was no significant difference between the baseline test scores of control and treatment students. This shows that randomization was well implemented. Being a cheater raised the baseline math test scores by 0.234 standard deviations (or sd). The effect was significant at the $1 \%$ level. Cheaters' benefits on their Chinese test scores were also positive and close to being significant. Being a cheater raised math and Chinese scores combined by $0.202 \mathrm{sd}$ (significant at the $1 \%$ level).

Applying the above regression to the evaluation tests (with evaluation math and Chinese scores as the outcome variable), we found that the treatment effects were still not significant. In other words, the pay-for-grades program failed to generate a significant impact on student test scores. This result mirrors the finding of Li et al. (2014).

More interestingly, we found that being a cheater, all other things being equal, raised a student's math and Chinese test scores by 0.212 and $0.357 \mathrm{sd}$, respectively (Column 4 and 
5). This effect on the Chinese test was statistically significant at the $1 \%$ level. The effect on the Chinese and math tests combined was $0.277 \mathrm{sd}$ (statistically significant at the $1 \%$ level, Column 6).

In summary, student test scores were not affected by the existence of pay-for-grades program. Cheating appeared to have a significant and positive impact on test scores in both the baseline and the evaluation tests.

$<$ Table 2 about here. $>$

\section{Determinants of Cheating}

Applying Regression 4 to the baseline sample, we obtain our baseline results, which are reported in Column 1 (math test only), 2 (Chinese test only), and 3 (both tests) of Table 3. The estimated effects of treatment status were all non-significant, consistent with our randomization design. The evaluation results are reported in Columns 4 to 6 . We find that the treatment effects were all small and statistically insignificant. This result shows that students in our sample did not respond to monetary incentives tied to test scores by cheating.

Was it possible that we failed to reject the null hypothesis of no treatment effect on cheating by chance when the null is actually true (i.e. commit a type-II error)? We calculated the statistical power, $1-\beta$. Defining the test statistic for the treatment effect under the null hypothesis that the treatment effect is zero as $\hat{T}=\frac{\hat{\beta}_{2}-0}{\hat{\sigma}}$, we used a two-tailed $\mathrm{Z}$ test. Power is a function of $\alpha$ (the significance level) and $g$ (the true treatment effect) for a given sample size. It is easy to show (details available upon request) that for $\alpha=0.05$, the power for Equation 4 (for math and Chinese combined) was very close to 1 for $g>0.1$. For $g=0.05$, the power was still high, 0.837. For $g<0.05$, the treatment effect becomes too small to be policy relevant. In summary, our statistical tests had high power for any reasonable level of true treatment effect. It is unlikely that our failure to reject the null hypothesis of no treatment effect was driven by a type-II error.

$<$ Table 3 about here.>

Across both periods, the baseline test scores appeared to be positively associated with cheating. We should not take this as evidence that students with higher test scores were more likely to cheat. First of all, all students in our sample were lower-performing students by definition. We cannot extrapolate these findings to other types of students. Second and more importantly, the causality probably goes the other way round, namely cheaters tended to receive higher scores, as we discussed previously.

In both periods, the benchmates' baseline test scores, holding other variables (including student own baseline test scores) fixed, tended to be negatively associated with cheating. This negative association was statistically significant at the $1 \%$ level in the baseline stage for math-only subsample, Chinese-only subsample, and the full sample. In the evaluation stage, the association was still negative and statistically significant at the $1 \%$ level for math. In other words, the test score gap between the student pairs tended to be negatively as- 
sociated with cheating by the lowest performing students. In other words, other things equal, a low-performing student is less likely to cheat when his/her benchmate has higher test scores. One possible explanation lies in the underlying social relationships between the student pairs. Suppose that a lower-performing student A wants to copy answers from his benchmate B. Cheating is more likely to go well with the help of the benchmate B. If B refuses to help or even makes an effort to hide his answers, cheating is less likely to occur despite the intention of $\mathrm{A}$. If the social distance between $\mathrm{A}$ and $\mathrm{B}$ is positively correlated with their test score gap, this helps to explain why cheating is negatively associated with the test score gap.

The positive correlations between social distance and test score gaps are a well-known phenomenon in most educational systems. In the US, this is usually framed as a racial issue - under-performing black students are more likely to interact with each other than with their higher-performing white peers (e.g., Echenique \& Fryer, 2007). However, the problem can exist independent of the racial issue. Carrell, Sacerdote, and West (2013) showed that cadets of similar test score levels tended to form distinct social groups in the United States Air Force Academy despite the existence of official policy that intentionally assigned them into mixed-ability peer groups. In our context, benchmate pairs are probably the most intensive social groups in a classroom. There is strong evidence that benchmate pairs tend to have similar test score levels. If we regress the benchmate test scores on a student's own test scores, we find that in the baseline period, when a student's own test scores increased by one sd, his benchmate test scores typically increased by $0.14 \mathrm{sd}$ (statistically significant at the $0.1 \%$ level, details available upon request).

In the baseline stage, there was significantly more cheating on the math test than on the Chinese test. The estimated coefficient for the math test dummy was 0.084 and it was statistically significant at the $1 \%$ level (Column 3 ). The estimated coefficient for the evaluation stage was small and statistically insignificant. These findings are consistent with the well-known result in the literature that cheating is more likely in math and sciences (Schab, 1991).

Except for the baseline Chinese test, Male did not have a significant impact on cheating. There was no strong evidence that cheating either increased or decreased by grade (details available upon request).

\section{Discussions}

Why didn't cash incentives for test scores generate more cheating in our experiment? We offer two possibilities. The first is the age of students in our study. How children respond to various forms of incentives has not been well understood (Rice \& Broome, 2004). What we do know is that children may sometimes find non-cash incentives more appealing. The use of token (but not pennies, which are usually less expensive for experimenters and more valuable for children) as an incentive device or reinforcement system for both ordinary children and children with intellectual disabilities is widespread in psychology (Matson \& Boisjoli, 2009). Children sometimes find small gifts, such as pencils and heart-shaped erasers, desirable; their tastes can change dramatically when they age (Hauber, Rice, Howell, 
\& Carmon, 1998; Rice, Howell, Hauber, \& Carmon, 1999). In China, the use of red flower sticker to reward young students is common. It is entirely possible that other types of incentives - though not cash incentives - may encourage primary school students to cheat more.

The motivations behind student cheating probably matters as well. A dominant motivation of cheating is the fear of failure (Syam, 2014; Van Yperen, Hamstra, \& van der Klauw, 2011). Less educated parents are more likely to use physical punishment when they are not satisfied with the child's outcome (Oreopoulos \& Salvanes, 2011). Migrant parents are usually poorly educated and are more likely to use negative parenting style including spanking to discipline their children than non-migrant parents in China (Zhang, Eisenberg, Liang, Li, \& Deng, in press). Younger students are more likely to be spanked, other things equal. ${ }^{2}$ Promising primary school students cash rewards for good test scores may not encourage more cheating among low-performing students; on the other hands, it is possible that threatening them with severe punishment (such as spanking) in case of exam failure might lead to significantly more cheating.

This motivation underlying cheating suggests that one possible explanation of why there was less cheating in the evaluation test is that students realized after the baseline test that the experiment is really low-stake: test scores were not reported back to their parents and there was nothing to fear. It also helps to explain why there is more cheating in math than in Chinese even when a multiple-choice format was used in both tests. We know that there is usually more cheating in math/sciences than in other types of exams (Schab, 1991). At first look, it seems to be just as easy for a student to copy a multiple-choice answer in a math test as in a Chinese test in our case. However, the motivations behind cheating are not necessarily the same. Students tend to be nervous about math regardless of their math skills. Students with math anxiety may adopt avoidance strategies in math classes including self-handicapping, disruptive behavior, and cheating (Hellum-Alexander, 2010). There is evidence that math anxiety is a more serious problem among migrant children in China Ye, Wei, and Liang (2012). Somewhat adding to the math anxiety is that the math questions in our study were slightly more difficult than the Chinese questions. In both baseline and evaluation tests, the average math correct rate is about $72 \%$, whereas the average Chinese correct rate is about $75 \%$. The difference in the correct rates is statistically significant at the conventional $95 \%$ level.

The last possibility is the design of our pay-for-grades program. We specifically design the program to only award three most-improving students in each classroom. In other words, students need to compete with each other tournament-style, contrasting many other similar programs where all students will be rewarded once they reach a performance target (Slavin, 2010). Despite the advantage in research design discussed in Li et al. (2014), once students realize that not everyone will be offered a reward, the motive for cheating is likely to diminish.

\footnotetext{
${ }^{2}$ Tao et al. (2004) find that, among over two thousands children aged from 1-14 surveyed in rural Anhui province of China, spanking is significantly more likely for younger children, low father education, boys, and non-single children.
} 


\section{Conclusion and Policy Implications}

We used a randomized control trial implemented in migrant primary schools in China to evaluate causal impact of providing under-performing students a pay-for-grades program on academic cheating. Here, cheating was defined according to a standard statistical algorithm that detects an abnormally large number of similar responses between a student and his benchmate. Our analysis show widespread cheat behavior in standardized test, especially on math tests and between bench pairs with a relatively convergent ability levels. This pattern of academic cheating did not differ by gender or by grade. Despite of that, we conclude that the pay-for-grade program did not increase the likelihood of cheating.

The implications of our findings are twofold. Firstly, educators in China need to pay attention to various forms of academic cheating, particularly in low-performing schools. Our results suggest that cheating is not isolated incidents but common in our sample. Secondly, using moderate incentive to encourage student learning did not lead to skewed incentives. Our findings suggest that the pay-for-grade program such as the one we studied, will not have unintended consequence on cheating. Yet we would also like to point out that pay-forgrades is likely context-dependent. Our design, which focuses on young primary students coupled with moderate financial incentive and low-stake test might not necessarily translate into other context. Case-by-case evaluation is needed before scaling up to other grade level with different incentive target.

\section{References}

Alutu, A. N., \& Aluede, O. (2006). Secondary schools students' perception of examination malpractices and examination ethics. Journal of human ecology, 20(4), 295-300.

Atkinson, J. W. (1957). Motivational determinants of risk-taking behavior. Psychological Review, 64 (6, Pt. 1), 359-372.

Behrman, J. R., Parker, S. W., Todd, P. E., \& Wolpin, K. I. (2015). Aligning learning incentives of students and teachers: Results from a social experiment in mexican high schools. Journal of Political Economy, 123(2), 325-364.

Bettinger, E. P. (2012). Paying to learn: The effect of financial incentives on elementary school test scores. Review of Economics and Statistics, 94(3), 686-698.

Carrell, S. E., Sacerdote, B. I., \& West, J. E. (2013). From natural variation to optimal policy? the importance of endogenous peer group formation. Econometrica, 81(3), $855-882$.

Cizek, G. J. (1999). Cheating on tests: How to do it, detect it, and prevent it. London: Routledge.

Davis, S. F., Drinan, P. F., \& Gallant, T. B. (2009). Cheating in school: What we know and what we can do. Wiley-Blackwell. 
Dearden, L. (2015). Parents risk lives climbing exam buildings to help hundreds of Indian students cheat. Independent. Retrieved from http://www.independent.co.uk/ news/world/asia/parents-risk-lives-climbing-exam-buildings-to-help -hundreds-of-indian-students-cheat-10120933.html

Diekhoff, G. M., Labeff, E. E., Shinohara, K., \& Yasukawa, H. (1999). College cheating in japan and the united states. Research in Higher education, 40(3), 343-353.

Eccles, J. (1983). Expectancies, values, and academic behaviors. In J. T. Spence (Ed.), Achievement and achievement motives: Psychological and sociological approaches. San Francisco, CA: W. H. Freeman and Company.

Echenique, F., \& Fryer, R. G. (2007). A measure of segregation based on social interactions. The Quarterly Journal of Economics, 122(2), 441-485.

Evans, E. D., \& Craig, D. (1990). Teacher and student perceptions of academic cheating in middle and senior high schools. The Journal of Educational Research, 84 (1), 44-53.

Finn, K. V., \& Frone, M. R. (2004). Academic performance and cheating: Moderating role of school identification and self-efficacy. The Journal of Educational Research, 97(3), 115-121.

Gu, Q., \& Brooks, J. (2008). Beyond the accusation of plagiarism. System, 36(3), 337 352.

Hauber, R. P., Rice, M. H., Howell, C. C., \& Carmon, M. (1998). Anger and blood pressure readings in children. Applied Nursing Research, 11(1), 2-11.

Hellum-Alexander, A. (2010). Effective teaching strategies for alleviating math anxiety and increasing self-efficacy in secondary students. (Unpublished master's thesis). The Evergreen State College.

Heyneman, S. P. (2004). Education and corruption. International Journal of Educational Development, 24(6), 637-648.

Heyneman, S. P., Anderson, K. H., \& Nuraliyeva, N. (2007). The cost of corruption in higher education. Comparative Education Review, 52(1), 1-25.

Jacob, B. A., \& Levitt, S. D. (2003). Rotten apples: An investigation of the prevalence and predictors of teacher cheating. The Quarterly Journal of Economics, 118(3), 843-877.

Kobiowu, S. V., \& Alao, F. (2009). The challenges of examination management in the developing societies: the nigerian scenario. International Journal of African \& AfricanAmerican Studies, $4(2)$. 
Le, V.-N. (2015). Should students be paid for achievement? a review of the impact of monetary incentives on test performance (Working paper No. 2014-006). Chicago, IL: NORC at the University of Chicago.

Li, T., Han, L., Zhang, L., \& Rozelle, S. (2014). Encouraging classroom peer interactions: Evidence from chinese migrant schools. Journal of Public Economics, 111, 29 - 45.

Matson, J. L., \& Boisjoli, J. A. (2009). The token economy for children with intellectual disability and/or autism: A review. Research in Developmental Disabilities, 30(2), 240-248.

McCabe, D. L. (2005). It takes a village: Academic dishonesty \& educational opportunity. Liberal education, 91 (3), 26-31.

McCabe, D. L., Feghali, T., \& Abdallah, H. (2008). Academic dishonesty in the middle east: Individual and contextual factors. Research in Higher Education, 49(5), 451-467.

Morais de Sa e Silva, M. (2015). Conditional cash transfers and improved education quality: A political search for the policy link. International Journal of Educational Development, 45, 169 - 181.

Murdock, T. B., Hale, N. M., \& Weber, M. J. (2001). Predictors of cheating among early adolescents: Academic and social motivations. Contemporary Educational Psychology, 26(1), 96 - 115.

Oreopoulos, P., \& Salvanes, K. G. (2011). Priceless: The nonpecuniary benefits of schooling. The journal of economic perspectives, 25(1), 159-184.

Osipian, A. L. (2009). Corruption hierarchies in higher education in the former soviet bloc. International Journal of Educational Development, 29(3), 321 - 330.

Ravitch, D. (2000). The great school wars: New York City, 1805-1973 (3rd ed.). Baltimore, MD: Johns Hopkins University Press.

Rice, M., \& Broome, M. E. (2004). Incentives for children in research. Journal of Nursing Scholarship, 36(2), 167-172.

Rice, M., Howell, C., Hauber, R., \& Carmon, M. (1999). Relationships among physical activity and weight, blood pressure readings, anger and anger expression in children. Unpublished manuscript University of Alabama at Birmingham.

Romero, M., Riascos, Á., \& Jara, D. (2014, August). A derivation of the optimal answercopying index and some applications (DOCUMENTOS CEDE No. 012061). UNIVERSIDAD DE LOS ANDES-CEDE.

Schab, F. (1991). Schooling without learning: Thirty years of cheating in high school. 
Adolescence, 26(104), 839.

Shei, C. (2005). Plagiarism, Chinese learners and Western convention. Taiwan Journal of TESOL, 2(1), 97-113.

Simões, A. A., \& Sabates, R. (2014). The contribution of bolsa família to the educational achievement of economically disadvantaged children in brazil. International Journal of Educational Development, 39, 141-156.

Slavin, R. E. (2010). Can financial incentives enhance educational outcomes? evidence from international experiments. Educational Research Review, 5(1), 68 - 80.

Syam, M. I. (2014). The factors that lead to cheating in exams and how to avoid them. GSTF Journal on Education (JEd), 1(2).

Tao, F., Zhang, H., Wang, D., Yang, S., Su, P., Feng, E., ... Zhang, L. (2004). The influence of sociocultural factors of spanking in Anhui province rural areas (in chinese). Chinese General Practice, 7(3), 172-174.

Van Yperen, N. W., Hamstra, M. R., \& van der Klauw, M. (2011). To win, or not to lose, at any cost: The impact of achievement goals on cheating. British Journal of Management, 22, S5-S15.

Vlaardingerbroek, B., Shehab, S. S., \& Alameh, S. K. (2011). The problem of open cheating and invigilator compliance in the lebanese brevet and baccalauréat examinations. International Journal of Educational Development, 31(3), 297 - 302.

Wigfield, A. (1994). Expectancy-value theory of achievement motivation: A developmental perspective. Educational Psychology Review, 6(1), 49-78.

Wollack, J. A. (1997). A nominal response model approach for detecting answer copying. Applied Psychological Measurement, 21(4), 307-320.

Wollack, J. A. (2004). Detecting answer copying on high-stakes tests. The Bar Examiner, $73,35-45$.

Xiong, Y. $(2015,3)$. The broken ladder: Why education provides no upward mobility for migrant children in china. The China Quarterly, 221, 161-184.

Ye, B., Wei, Q., \& Liang, D. (2012). Research on mathematics anxiety of the migrant workers' children in junior middle school - evidence from Guilin shiyou middle school and Chuanshan middle school (in Chinese). Journal of Mathematics Education, 21(3), 43-46.

Zhang, G., Eisenberg, N., Liang, Z., Li, Y., \& Deng, H. (in press). The relations of migrant status and parenting to chinese adolescents' adjustment. International Journal of 
Behavioral Development, O(0). doi: 10.1177/0165025415627699 
Table 1

Summary statistics of the analytical sample

\begin{tabular}{|c|c|c|c|}
\hline & $\begin{array}{l}\text { Difference } \\
\text { (1) }\end{array}$ & $\begin{array}{l}\text { Control } \\
(2)\end{array}$ & $\begin{array}{l}\text { Treatment } \\
\text { (3) }\end{array}$ \\
\hline \multicolumn{4}{|l|}{ A: Baseline } \\
\hline pre-test & $\begin{array}{l}0.0253 \\
(0.0631)\end{array}$ & -0.764 & -0.790 \\
\hline Benchmate pre-test & $\begin{array}{l}-0.0356 \\
(0.0750)\end{array}$ & -0.0655 & -0.0299 \\
\hline Cheater (math) & $\begin{array}{l}0.0238 \\
(0.0313)\end{array}$ & 0.191 & 0.167 \\
\hline Cheater (Chinese) & $\begin{array}{l}-0.0123 \\
(0.0239)\end{array}$ & 0.0896 & 0.102 \\
\hline Male & $\begin{array}{l}-0.0799^{* *} \\
(0.0404)\end{array}$ & 0.516 & 0.596 \\
\hline Grade & $\begin{array}{l}0.0653 \\
(0.0867)\end{array}$ & 4.451 & 4.385 \\
\hline \multicolumn{4}{|l|}{ B: Evaluation } \\
\hline post-test & $\begin{array}{l}-0.0793 \\
(0.0806)\end{array}$ & -0.530 & -0.451 \\
\hline Cheater (math) & $\begin{array}{l}0.00450 \\
(0.0195)\end{array}$ & 0.0627 & 0.0582 \\
\hline Cheater (Chinese) & $\begin{array}{l}0.0110 \\
(0.0256)\end{array}$ & 0.116 & 0.105 \\
\hline $\mathrm{N}$ & 610 & 335 & 275 \\
\hline
\end{tabular}

Note: "Difference" refers to the difference between control and treatment groups. Standard errors of t-tests reported in parenthesis. ${ }^{*} p<0.1,{ }^{* *} p<0.05,{ }^{* * *} p<0.01$. 


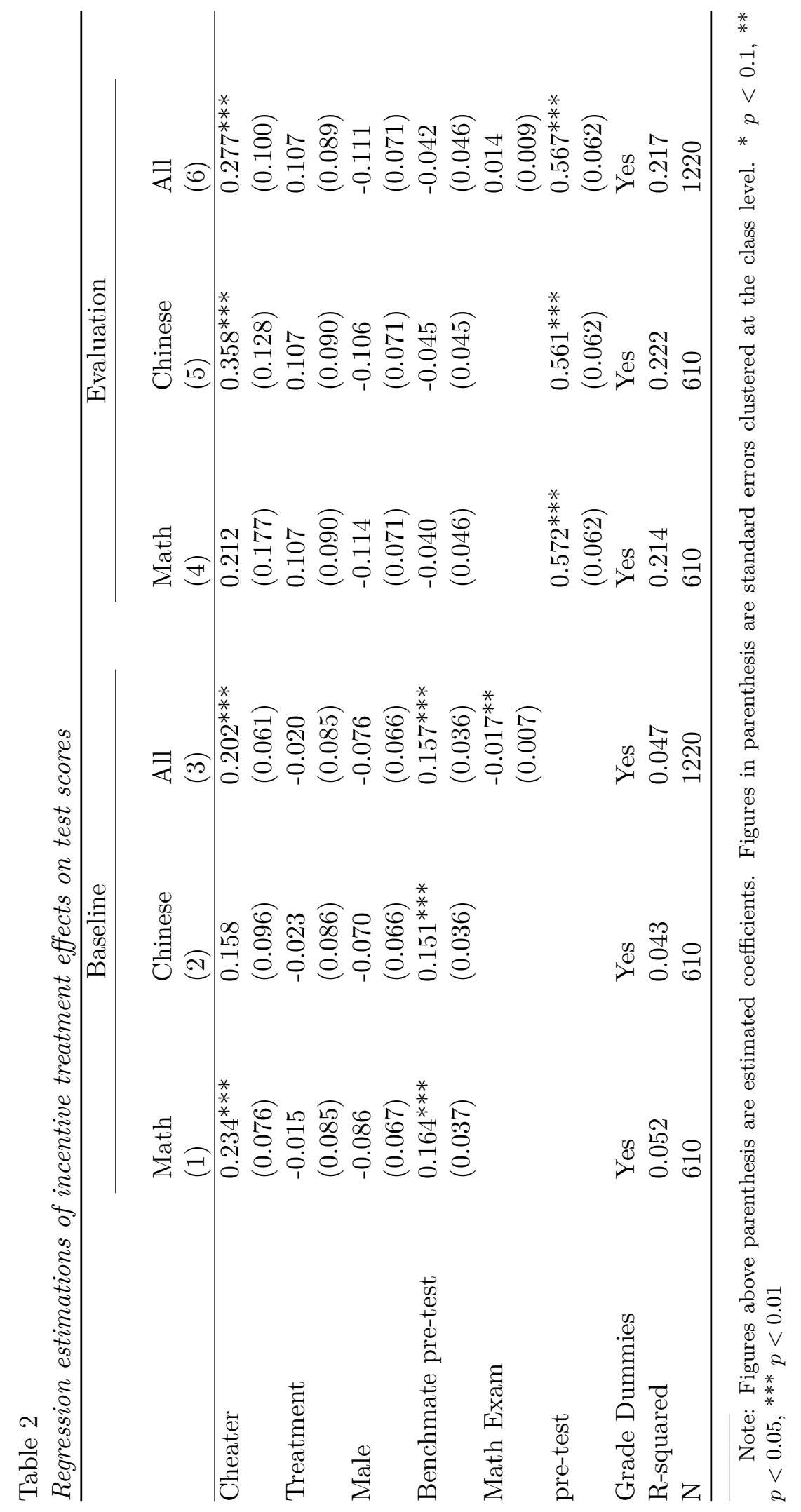




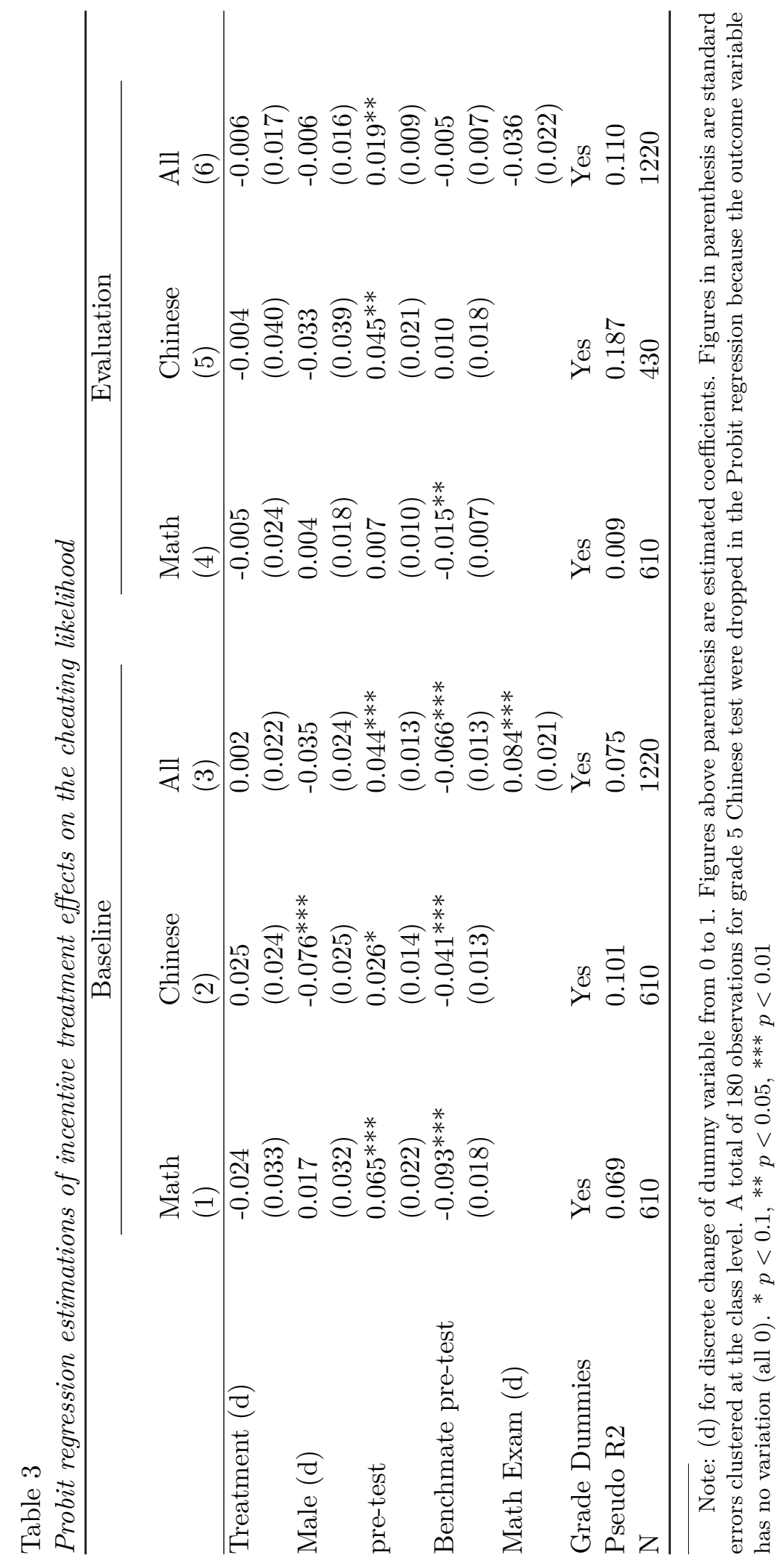

